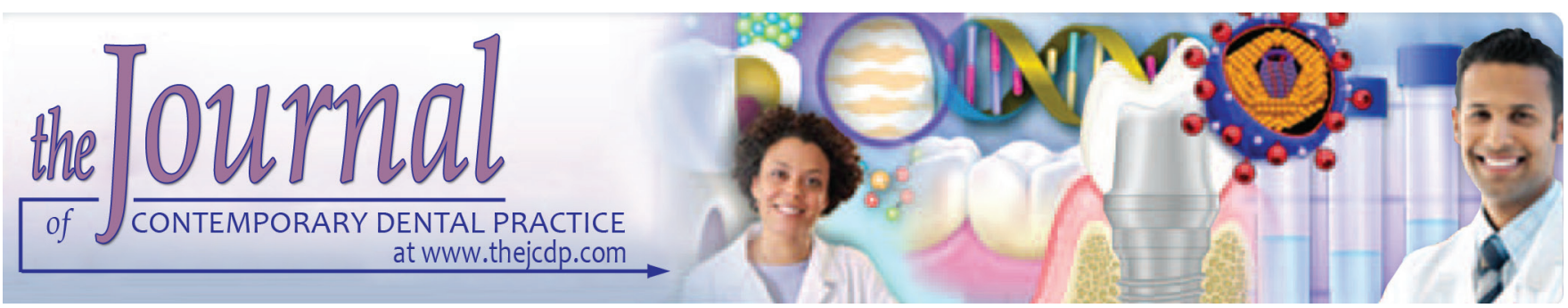

\title{
Effect of Radiotherapy on Cariogenic Organism Streptococcus sobrinus in Saliva in Head and Neck Cancer: A Clinical Study
}

${ }^{1}$ Sonali Kapoor, ${ }^{2}$ Shilpi R Daveshwar, ${ }^{3}$ Kesha Sheth, ${ }^{4}$ Meena R Daveshwar, ${ }^{5}$ Renu Batra, ${ }^{6}$ Vineet Agrawal

\begin{abstract}
Aim: Aim of the study was to assess salivary Streptococcus sobrinus in head and neck cancer using quantitative polymerase chain reaction (PCR).

Materials and methods: Unstimulated saliva samples were collected from head and neck cancer patient preradiotherapy. Unstimulated saliva samples were collected from oral and laryngeal cancer patients after 6 weeks of radiotherapy (dose $60 \mathrm{~Gy}$ ). The subjects were explained not to consume solids or liquids or carry out any dental hygiene activity 1 hour prior to saliva collection. Accumulated unstimulated saliva was collected in cylindrical tube through funnel. The collected saliva was then transferred to Eppendorf tube containing Tris-ethylenediaminetetraacetic acid (EDTA) (TE) buffer and was transported to lab for real-time PCR analysis.
\end{abstract}

Results: Streptococcus sobrinus significantly increased postradiotherapy as compared with preradiotherapy in head and neck cancer patients.

Conclusion: Within the limitation of this study, we conclude that amount of $S$. sobrinus increases postradiotherapy in head and neck cancer patients.

Clinical significance: As radiation therapy has harmful effects on hard and soft tissues of oral cavity, dentists should provide motivation for oral health care to the patients.

Keywords: Dental caries, Oral cancer, Polymerase chain reaction. How to cite this article: Kapoor S, Daveshwar SR, Sheth K, Daveshwar MR, Batra R, Agrawal V. Effect of Radiotherapy on Cariogenic Organism Streptococcus sobrinus in Saliva in Head and Neck Cancer: A Clinical Study. J Contemp Dent Pract 2018;19(8):929-932.

\footnotetext{
${ }^{1-3,5,6}$ Department of Conservative Dentistry, Esthetics and Endodontics, Manubhai Patel Dental College and Hospital Vadodara, Gujarat, India

${ }^{4}$ Department of Pathology, Baroda Medical College \& S.S.G Hospital, Vadodara, Gujarat, India

Corresponding Author: Sonali Kapoor, Department of Conservative Dentistry, Esthetics and Endodontics, Manubhai Patel Dental College and Hospital, Vadodara, Gujarat, India Phone: +919825323057, e-mail: docsonali@gmail.com
}

Source of support: Nil

Conflict of interest: None

\section{INTRODUCTION}

The head and neck region of human body contains vital organs that are closely situated around each other. Malignant tumors of head and neck occur in the oral cavity, pharynx, paranasal sinuses, larynx, thyroid gland, parathyroid gland, salivary glands, bronchial tubes, and esophagus. ${ }^{1}$ Irradiation is one of the modes of treatment used for cancers in these regions. ${ }^{2}$ During treatment, irradiation affects the salivary glands and dentition, leading to many detrimental side effects, such as mucositis, xerostomia, and radiation caries. Radiotherapy can produce severe changes in oral microbiota. ${ }^{3}$

The major organisms leading to dental decay are Streptococcus mutans, Lactobacilli, and Streptococcus sobrinus. ${ }^{4-6}$

A few decades ago, most of the knowledge on the detection of the oral microbiome was based mainly on culture techniques. ${ }^{7}$ More recently, PCR has been introduced. Different types of clinical samples of blood, sweat, semen, hair, and saliva are nowadays used for PCR analyses. ${ }^{8}$ Saliva acts as a biomarker material for diagnostic tests in oral as well as systemic diseases. Investigations regarding bacterial and fungal profiles in saliva are popular and also have reliable results. ${ }^{9}$

In this study, quantitative real-time PCR was used for assessment of cariogenic $S$. sobrinus in saliva of head and neck cancer patients undergoing radiotherapy.

\section{MATERIALS AND METHODS}

Study population consisted of 30 head and neck cancer patients (15 oral cancer and 15 laryngeal cancer). All 30 


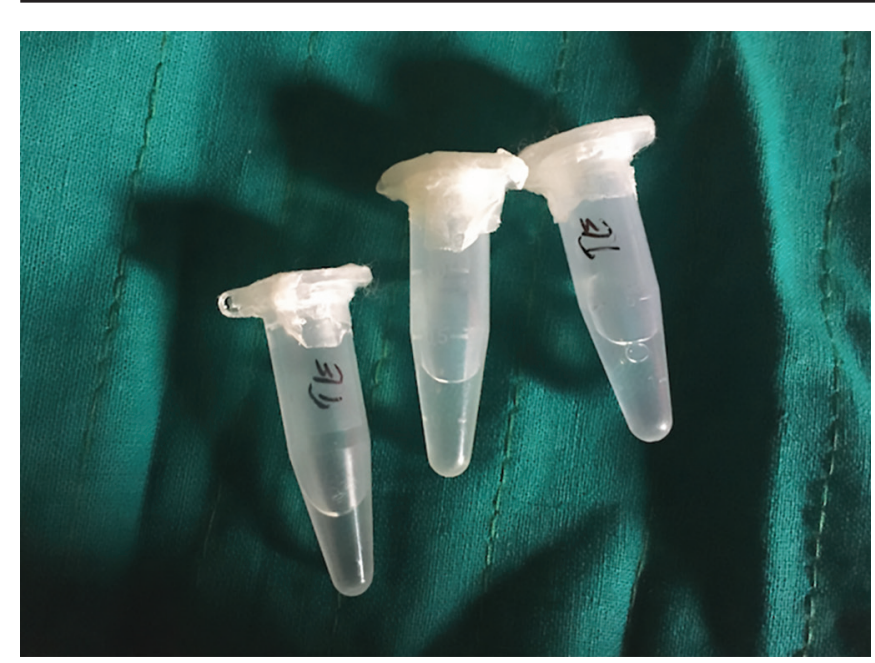

Fig. 1: Eppendorf tube containing TE buffer

patients were screened preradiotherapy and postradiotherapy. Saliva was taken from the same individuals preradiotherapy and postradiotherapy.

- Group I: Preradiotherapy patients

- Group II: Postradiotherapy patients

\section{For Saliva Sample Collection}

Unstimulated saliva was collected from head and neck cancer patients preradiotherapy. Unstimulated saliva was collected from head and neck cancer patients immediately after 6 weeks of radiotherapy (dose $60 \mathrm{~Gy}$ ). The subjects were explained not to consume solids or liquids or carry out any dental hygiene activity 1 hour prior to saliva collection.

Accumulated unstimulated saliva was collected in cylindrical tube through funnel. This collected saliva was then transferred to Eppendorf tube containing TE buffer (Fig. 1), which was transported to lab for real-time PCR analysis (Fig. 2).

\section{The PCR Procedure}

Real-time PCR analysis for detection of S. sobrinus was done at the Department of Microbiology, Maratha Mandal Nathajirao G. Helgekar Institute of Dental Science, Belagavi, Karnataka, India. The PCR procedure was as follows:

- The collected samples were transferred to the tube containing TE buffer.

- They were centrifuged at 5,000 rpm for 5 minutes.

- To it $500 \mathrm{~mL}$ fresh TE buffer was added with the help of sterile micropipette and it was centrifuged for 3 to 4 minutes and repeated 3 to 4 times.

- The supernatant was discarded and $50 \mathrm{~mL}$ lysis buffer I was added with the help of sterile micropipette and it was vortexed and kept for 5 minutes.

Then micropipette lysis buffer II for lysis of bacteria and $10 \mathrm{~mL}$ proteinase- $\mathrm{K}(100 \mu \mathrm{g} / \mathrm{mL})$ for digestion of

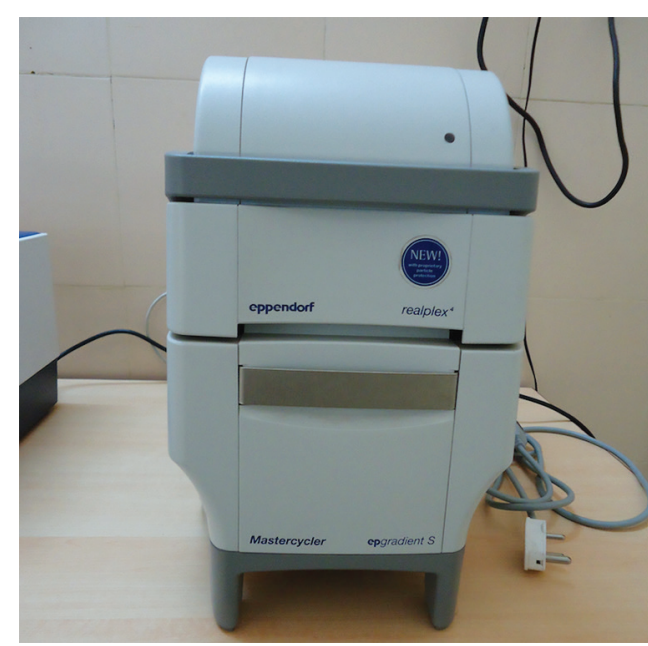

Fig. 2: Polymerase chain reaction machine

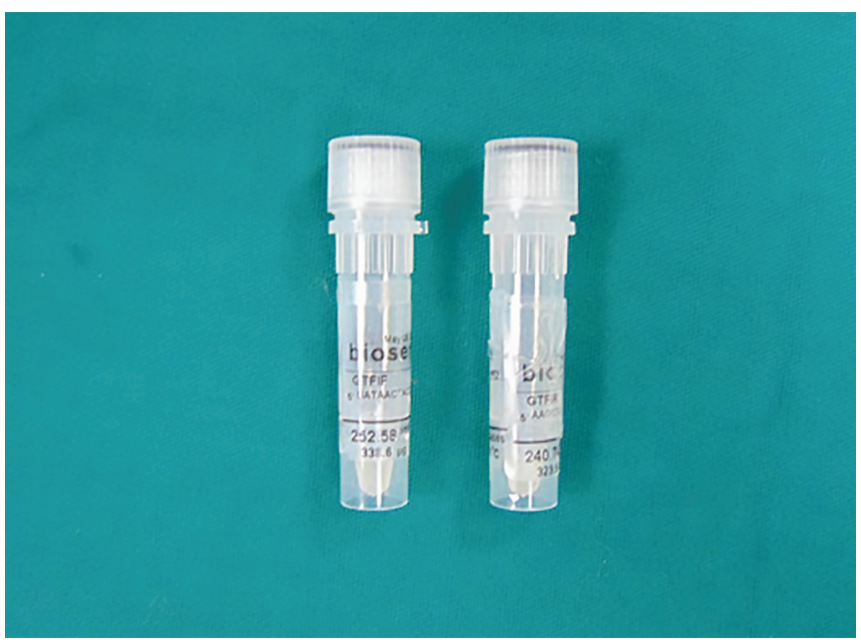

Fig. 3: Specific PCR primers for S. sobrinus

protein and removal of contamination from preparations of nucleic acid were added, and it was vortexed vigorously. Then it was kept in water bath for 2 hours and then in boiling water bath for 10 minutes.

The following set of PCR primers were used, which are specific to $S$. sobrinus (Fig. 3).

- Forward primer: GTFI-Forward 5'-GATAACTAC CTGACAGCTGACT-3'

- Reverse primer: GTFI-Reverse 5'-AAGCTGCCTT AAGGTAATCACT-3'

A mixture was prepared and aliquoted into each tube. The premix contained following components in a final volume of $20 \mu \mathrm{L} /$ aliquot. (Qiagen Quantitect SYBR Green PCR master mix was used which contains $2.5 \mathrm{mM} \mathrm{MgCl}_{2}$. In addition, the master mix contains Taq polymerase enzyme, dNTP mix, and SYBR Green dye.)

- Polymerase chain reaction master mix after thawing was gently vortexed and briefly centrifuged.

- A thin-walled PCR tube was placed on ice and the following components for each $50 \mu \mathrm{L}$ reaction were added. - Quantitect SYBR green master mix: $10 \mu \mathrm{L}$ 
- S. sobrinus (Forward primer): $0.3 \mu \mathrm{L}$ (10 pmol)

- S. sobrinus (Reverse primer): $0.3 \mu \mathrm{L}$ (10 pmol)

- Template deoxyribonucleic acid (DNA): $3 \mu \mathrm{L}$ $(<1 \mu \mathrm{g} /$ reaction $)$

- Water: Added to make final volume to $20 \mu \mathrm{lL}$

- The samples were gently vortexed and slowly the speed was reduced.

- The tubes were then placed in real-time thermal cycler (Eppendorf).

The PCR conditions were as follows:

Initial denaturation $\left(95^{\circ} \mathrm{C}, 5\right.$ minutes $)$

Denaturation $\left(95^{\circ} \mathrm{C}, 30\right.$ minutes)

Annealing $\left(56^{\circ} \mathrm{C}, 1\right.$ minute $)$

35 cycles

Extension $\left(72^{\circ} \mathrm{C}, 1\right.$ minute $)$

\section{RESULTS}

\section{The PCR Analysis}

All the 30 samples showed presence of S. sobrinus in PCR readings. In the real-time PCR SYBR green method, the SYBR green dye binds with double-stranded DNAs which were specifically amplified by $S$. sobrinus-specific primers. The dye emits the fluorescence in the form of graph. The graph was plotted as the amount of fluorescence against the number of cycle. Serial dilutions of standard samples were run along with the test sample to plot the standard graph.

Realplex software graph results show increase in S. sobrinus from baseline postradiotherapy, as given in Graph 1. Statistical analysis was done using independent t-test to check S. sobrinus postradiotherapy (Table 1). The $\mathrm{t}$-value of group II (2.151) was greater than group I (0.958). The mean difference of group II (3.81419) was also greater than group I (1.83729). The p-value of group I was 0.352 . The PCR readings of group I were statistically insignificant as the $t$-value was near to 0 and $p>0.05$. There was a statistically significant difference in PCR readings of group II as the $p$-value $<0.05$. This depicted that $S$. sobrinus was significantly $(\mathrm{p}<0.05)$ higher postradiotherapy as compared with preradiotherapy.

\section{DISCUSSION}

Radiation therapy in the head and neck region results in predictable reduced salivation. Irradiation damages the serous cells of salivary glands producing thick ropy saliva and markedly reduced salivation.

Xerostomia leads to dental and oral diseases. This occurs as there is an imbalance in normal oral cavity homeostasis, leading to increased dental caries and changes in taste, speech, eating habits; thus affecting life of an individual. Dental caries occurs due to complex interaction between acid-producing bacteria, fermentable sugars, and host factor. ${ }^{10}$ Radiation caries is a destructive and rapidly progressing type of dental caries.

Kang et $\mathrm{al}^{11}$ stated that presence of $S$. sobrinus in healthy individuals was lower as compared with individuals with head and neck tumors and the results were statistically significant. As not many studies are done on S. sobrinus, the present study was done on S. sobrinus.

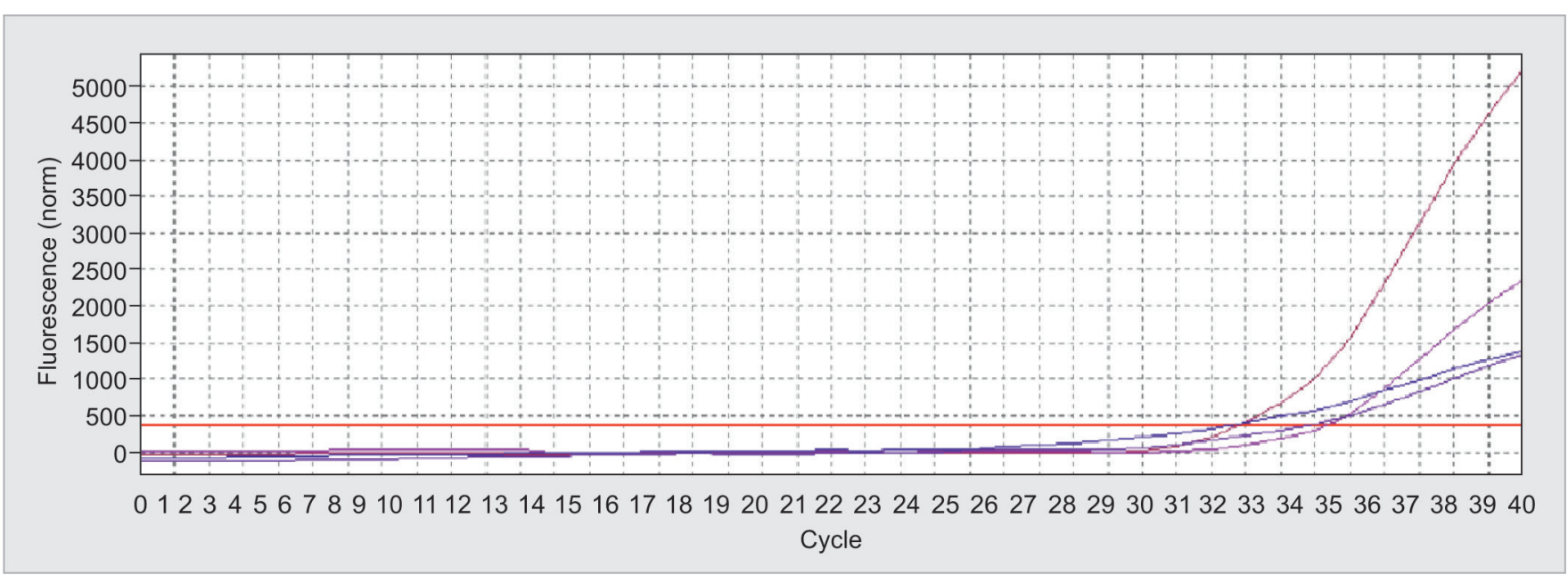

Graph 1: Realplex software image indicating the amount of fluorescence against the number of cycles, and showing detection of $S$. sobrinus colony from baseline

Table 1: Statistical analysis of S. sobrinus in groups I and II

\begin{tabular}{|c|c|c|c|c|c|c|c|}
\hline & \multirow[b]{2}{*}{$t$-value } & \multirow{2}{*}{$\begin{array}{l}\text { Degree of } \\
\text { freedom }\end{array}$} & \multirow[b]{2}{*}{$p$-value } & \multirow[b]{2}{*}{ Mean difference } & \multirow{2}{*}{$\begin{array}{l}\text { Standard error } \\
\text { difference }\end{array}$} & \multicolumn{2}{|c|}{$\begin{array}{l}95 \% \text { confidence interval of } \\
\text { the difference }\end{array}$} \\
\hline & & & & & & Lower & Upper \\
\hline log_S. sobrinus_Pre & 0.958 & 16 & 0.352 & 1.83729 & 1.91836 & -2.22947 & 5.90404 \\
\hline $\log$ S. sobrinus Post & 2.151 & 18 & 0.045 & 3.81419 & 1.77341 & 0.08840 & 7.53999 \\
\hline
\end{tabular}


There is a high carcinogenicity of $S$. sobrinus compared with $S$. mutans as it is highly acid-forming organism. But S. sobrinus is detected only in a small number; S. sobrinus is commonly found along with $S$. mutans, where S. mutans are in majority compared with $S$. sobrinus. With the use of $\mathrm{PCR}$, it can be concluded that there is a high prevalence of S. sobrinus than conventional culture methods. Although S. mutans are more in comparison to $S$. sobrinus in dental plaque, ${ }^{12}$ the main cause for reduced growth and inadequate detection of S. sobrinus is due to its incapability to metabolize $\mathrm{N}$-acetylglucosamine, which is an essential amino acid sugar found in oral cavity. ${ }^{13}$

The S. sobrinus proliferates when the high fermentable carbohydrates are consumed or there is an acidic oral environment. ${ }^{14}$ In the present study due to radiotherapy, there was reduced salivary flow leading to acidic saliva, so there was increase in S. sobrinus postradiotherapy.

Plaque samples were not selected due to high variability of plaque coating and presence of cariogenic microbes on individual tooth surfaces. ${ }^{15}$ Presence of saliva is in equilibrium to the oral cavity, thus making a good biomarker for microbial detection. ${ }^{16}$

Zhang et a ${ }^{17}$ studied oral microbiota in nasopharyngeal carcinoma postradiotherapy patients. In this study, Streptococcus spp. was significantly higher postirradiation.

$\mathrm{Hu}$ et $\mathrm{al}^{18}$ also found Streptococcus spp. significantly higher postradiotherapy in head and neck irradiated patients.

\section{CONCLUSION}

Thus, within the limitations of this study, it can be concluded that presence of $S$. sobrinus significantly increases in saliva postradiotherapy in head and neck cancer patients as compared with preradiotherapy patients.

\section{CLINICAL SIGNIFICANCE}

As the irradiation affects the hard tissue and increases the chances of dental caries, measures should be taken for oral health care. The measures that can be taken for oral health care are:

- Patient motivation.

- Changing the dietary habits. Frequency of sugar intake should be reduced and more of fibrous food should be taken.

- Fluoride mouthwash should be given to reduce the risk of dental caries.

- For xerostomia, salivary substitutes like cevimeline and pilocarpine can be given to the patients.

\section{ACKNOWLEDGMENT}

The authors provide sincere thanks to Dr Kishore Bhat (Director, Professor and Head of Department of Microbiology, NGH Institute of Dental Sciences and
Research, Belagavi, Karnataka, India) for carrying out PCR work.

\section{REFERENCES}

1. Nagler RM. The enigmatic mechanism of irradiationinduced damage to the major salivary glands. Oral Dis 2002 May;8(3):141-146.

2. Walker MP, Wichman B, Cheng AL, Coster J, Williams KB. Impact of radiotherapy dose on dentition breakdown in head and neck cancer patients. Pract Radiat Oncol 2011;1(3):142-148.

3. Tong HC, Gao XJ, Dong XZ. Non-mutans streptococci in patients receiving radiotherapy in the head and neck area. Caries Res 2003 Jul-Aug;37(4):261-266.

4. van Houte J. Role of micro-organisms in caries etiology. J Dent Res 1994 Mar;73(3):672-681.

5. Loesche WJ. Role of Streptococcus mutans in human dental decay. Microbiol Rev 1986 Dec;50(4):353-380.

6. Beighton D. The complex oral microflora of high-risk individuals and groups and its role in the caries process. Community Dent Oral Epidemiol 2005 Aug;33(4):248-255.

7. Leung WK, Jin LJ, Samaranayake LP, Chiu GK. Subgingival microbiota of shallow periodontal pockets in individuals after head and neck irradiation. Oral Microbiol Immunol 1998 Feb;13(1):1-10.

8. Valones MA, Guimarães RL, Brandão LA, de Souza PR, de Albuquerque Tavares Carvalho A, Crovela S. Principles and applications of polymerase chain reaction in medical diagnostic fields: a review. Braz J Microbiol 2009 Jan;40(1):1-11.

9. D'Amario M, Barone A, Marzo G, Giannoni M. Caries-risk assessment: the role of salivary tests. Minerva Stomatol 2006 Jul-Aug;55(7-8):449-463.

10. Selwitz RH, Ismail AI, Pitts NB. Dental caries. Lancet 2007 Jan;369(9555):51-59.

11. Kang MS, Oh JS, Kim HJ, Kim HN, Lee IK, Choi HR, Kim OJ, Ko YJ, Lim WB, Park HJ, et al. Prevalence of oral microbes in the saliva of oncological patients. J Bacteriol Virol 2009 Dec;39(4):277-285

12. Okada M, Soda Y, Hayashi F, Doi T, Suzuki J, Miura K, Kozai K. PCR detection of Streptococcus mutans and S. sobrinus in dental plaque samples from Japanese pre-school children. J Med Microbiol 2002 May;51(5):443-447.

13. Homer KA, Patel R, Beighton D. Effects of $\mathrm{N}$-acetylglucosamine on carbohydrate fermentation by Streptococcus mutans NCTC 10449 and Streptococcus sobrinus SL-1. Infect Immun 1993 Jan;61(1):295-302.

14. Bretz WA, Krahn DD, Drury M, Schork N, Loesche WJ. Effects of fluoxetine on the oral environment of bulimics. Oral Microbiol Immunol 1993 Feb;8(1):62-64.

15. Lindquist B, Emilson CG. Distribution and prevalence of mutans streptococci in the human dentition. J Dent Res 1990 May;69(5):1160-1166.

16. Emilson CG. Prevalence of Streptococcus mutans with different colonial morphologies in human plaque and saliva. Scand J Dent Res 1983 Feb;91(1):26-32.

17. Zhang J, Liu H, Liang $X$, Zhang M, Wang R, Peng G, Li J. Investigation of salivary function and oral microbiota of radiation caries-free people with nasopharyngeal carcinoma. PLoS One 2015 Apr;10(4):e0123137.

18. Hu YJ, Wang Q, Jiang YT, Ma R, Xia WW, Tang ZS, Zheng L, Jing PL, Huang ZW. Characterization of oral bacterial diversity of irradiated patients by high-throughput sequencing. Int J Oral Sci 2013 Mar;5(1):21-25. 